\title{
Cristianismo, secularização e caridade: a Filosofia da Religião pós-metafísica de Gianni Vattimo ${ }^{1}$
}

\author{
Christianity, secularization and charity: \\ the postmetaphysical Philosophy of Religion of Gianni Vattimo
}

Marcelo Barreira

RESUMO

No livro "Acreditar em Acreditar", Vattimo retoma o pensamento de Nietzsche e Heidegger, articulando-os com a tradição quenótica cristã. Em sua tentativa de vincular o cristianismo e uma perspectiva pós-metafísica e a favor da laicidade do Estado, Vattimo faz uma leitura heideggeriana da teoria antropológica de Girard, entrelaçando o anúncio da "morte de Deus" e a Verwindung da ontotelogia pela cáritas da secularização". Por fim, a retomada caritativa e criativa do passado é um processo dialógico e emancipatório que ocorre por meio da escuta da tradição pelo filtro hermenêutico da pietas.

PALAVRAS-CHAVE: Kénosis, Verwindung; Cáritas, Pietas, Vattimo.

ABSTRACT

In the book Believe, Vattimo retakes the thought of Nietzsche and Heidegger, linking them with the Christian kenotic tradition. In his attempt to link Christianity and the post-metaphysical perspective with laicity of secular state, Vattimo makes a Heideggerian reading of anthropological theory of Girard, intertwining the announcement of the "death of God" and the ontotheological Verwindung by the "Caritas secularization". Finally, the charitable and creative recovery of the past is a dialogical and emancipatory process that takes place through listening to the tradition by the hermeneutical filter of pietas.

KEYWORDS: Kenosis, Verwindung; Caritas, Pietas, Vattimo.

\footnotetext{
${ }^{1}$ Recebido em 01/11/2017. Aprovado em 31/12/2017.

2 Doutor em Filosofia pela Universidade Estadual de Campinas. Professor do Departamento de Filosofia da Universidade Federal do Espírito Santo (UFES). Email: marcelobarreira@ymail.com
} 


\section{Introdução}

pensamento de Gianni Vattimo sobre a religião se tornou paradigmático numa abordagem pós-metafísica. Eis brevemente sua biografia intelectual: doutorou-se em 1959, sob a orientação de Pareyson, e passa a estudar mais intensamente as obras de Nietzsche e Heidegger, chegando a fazer uma especialização em Heidelberg com Karl Löwith e HansGeorg Gadamer, autor que teve suas obras traduzidas por ele para o italiano. Desde 1964, ministra Estética na Faculdade de Lettere e Filosofia da Universidade de Turim, sendo também, a partir de 1982, professor de Filosofia Teorética. $\bigcirc$ autor torinense se faz presente na mídia italiana a partir de 1950, quando participou de programas televisivos da RAI, adquirindo ampla visibilidade. Tendo assumido, pela segunda vez, o mandato de deputado do Parlamento Europeu. Ademais, Vattimo escreve artigos para o público em geral - no semanário L'Espresso ou para os jornais La Repubblica e La Stampa -, além de textos mais rigorosos de teor propriamente acadêmico, tendo publicado mais de 20 livros publicados.

Nos anos 90, Vattimo se interessa pela religião e reassume sua fé cristã. Como marco desse retorno, Vattimo escreve um livro com o curioso título de "Acreditar em Acreditar". Publicado na Itália em 1996, essa obra foi escrita na primeira pessoa do singular e avalia que a guinada em sua pesquisa aconteceu, sobretudo, com a morte de pessoas próximas por conta da Aids, além de acontecimentos como a queda do muro de Berlim, que, para ele, foi influenciado pela ação do Papa João Paulo Il; outro acontecimento, mais regional, foi o surpreendente peso político da hierarquia eclesiástica italiana.

Esses fatores pessoais e históricos fizeram Vattimo ler com um diferente e original olhar não só as obras de Nietzsche e Heidegger, mas também o próprio cristianismo, em que considera, ou crê, acreditar. De um ponto de vista conceitual, tal olhar seria devedor de certas interferências culturais inauguradas pelo dramático anúncio nietzschiano do assassinato do "Deus" moral (NIETZSCHE, 1981, seções 108, 125 e 343). Esse diagnóstico de nossa atmosfera cultural (DERRIDA \& VATTIMO, 2000, p. 96-97) ajudou a clarear o transfundo histórico-ontológico do eclipse das metanarrativas (grand récit) e dos macrossistemas filosóficos. Isso exigiu da filosofia a construção de novos referenciais conceituais para o colóquio contemporâneo entre esferas culturais. Um desses novos 
referenciais foi a hermenêutica contemporânea que, de modo especial, estabeleceu novas e promissoras abordagens entre a filosofia e a religião (VATTIMO, 2004, p. 112).

\section{1 - Hermenêutica pós-metafísica do cristianismo}

Retomando a crítica de Ricoeur (1996, p. 165-173) à fenomenologia da religião, a hermenêutica não preconiza uma essencialidade do sagrado como pretendiam Rudolf Otto e, em seus passos, Mircea Eliade. Tal pretensão seria inviável e até inócua, pois a hermenêutica reconhece que as tradições filosóficas, como a própria hermenêutica, bem como as experiências religiosas só acontecem na relatividade de uma situação histórica. Daí vem o empreendimento de Vattimo em articular dois movimentos histórico-culturais nos quais se insere: a tradição hermenêutica e a herança religiosa cristã.

No empreendimento hermenêutico para sustentar seu ponto de vista, Vattimo se utiliza de vários autores, estabelecendo uma original conexão entre eles. Uma primeira conexão foi a que nosso autor estabelece entre a ontologia heideggeriana e a hipótese antropológica de René Girard conforme foi apresentada no livro intitulado de "A Violência e o Sagrado" (1991). Para Girard, o "sagrado natural" refere-se ao modo como as sociedades tradicionais teriam lidado com o conflito social em suas origens: pela violência de uma "lógica vitimária". O sacrifício e a expiação da vítima, que adquire atributos sagrados, permitiriam aplacar as rivalidades advindas do impulso mimético de cada membro de uma sociedade quanto à apropriação de coisas dos outros. Seria, portanto, esse sacrifício da vítima - por meio de um culto coletivo a ela - que restabeleceria a convivência entre os membros da sociedade. Nessa obra, no entanto, Girard aponta a disparidade entre o cristianismo e essa violência do "sagrado natural". A mensagem cristã seria oposta ao "sagrado natural" porque, no Evangelho, a revelação cristã do Deus-amor seria antagônica à lógica da violência para resolver conflitos sociais. A crucificação mostra isso. A crucificação não teria sido fruto da justiça divina por causa da "queda original" e sim o sinal da presença de vestígios naturais do sagrado na mentalidade judaica daquela época, incapaz de escutar a mensagem de acolhida do diferente trazida por Jesus (VATTIMO, 1999, p. 78). 
Em sua tentativa de vincular o cristianismo e uma perspectiva pós-metafísica, Vattimo faz uma leitura heideggeriana da teoria antropológica de Girard. Isso foi feito pelo entrelaçamento entre a morte de Deus e o fim do sagrado natural. A ontoteologia exibe o mesmo padrão violento do "sagrado natural". A ontoteologia é o processo teórico que entende realidade última a partir de um objetivismo e de uma ahistoricização de Deus (VATTIMO, 1999, p. 45). Vattimo reconhece um estímulo à violência tanto na ontoteologia quanto no sagrado natural. A dissolução da metafísica decorre do diagnóstico nietzschiano da morte do "Deus" moral em conjunto com a "superação" heideggeriana da "constituição ontoteológica" (GUARINO, 2009, p. 20). A verdade da metafísica, de um ponto de vista heideggeriano, identifica o ser com a objetividade e o fundamento (VATTIMO, 2004, p. 113). A metafísica acredita que há uma única ou privilegiada maneira de se acessar a "realidade". Disso advém a sua intolerância para com os outros pontos de vista, o que exige o silêncio de todos que não concordam com sua correspondência objetivista (adæquatio) aos dados (VATTIMO, 1992, p. 95). A cortante e incontroversa evidência do ser em sua peremptoriedade e em seu fundamento (Grund] absoluto e último não deixa mais espaço para perguntas posteriores, é como uma autoridade que cala e impõe sem "dar explicações" (VATTIMO, 1999, p. 52).

Essa atitude de silenciamento opõe-se à caridade (cáritas). Moldado pelo mito da Encarnação e pelo subsequente enfraquecimento dos poderes absolutos, o cristianismo traz em seu bojo o princípio da cáritas. $\bigcirc$ Deus não-violento e não-absoluto da época pósmetafísica é fruto da encarnação, da kénosis. Kénosis é um termo usado por Paulo em sua Carta aos Filipenses (FI 2, 7) que se tornou um conceito teológico referente a esse esvaziamento e/ou enfraquecimento da onipotência divina com a encarnação de Deus (VATTIMO, 1998, p. 45). O cristianismo transmite uma mensagem de amor e de caridade em sua acolhida do outro. De acordo com Vattimo, Jesus Cristo nos revela que a religiosidade não consiste no sacrifício, mas em amar a Deus e ao próximo [GIRARD \& VATTIMO, 2010, p. 29). Nesse sentido, o debilitamento do divino e o acolhimento do outro balizaram indelevelmente a posterior tradição cristã (VATTIMO, 2004, p. 63). Dessa forma, no âmago da matriz mítica cristã, a kénosis divina teria rompido com a lógica vitimária para acolher caritativamente o outro, dando início a um longo processo que, no Ocidente, veio a desembocar na secularização democrática. 


\section{2 - A "caritas da secularização" como chave de leitura da tradição cristã}

Essa cáritas secularizante e democratizante caracteriza a mais alvissareira tradição cristã. Ela permite uma visão do mundo que escapa da violência da metafísica (GUARINO, 2009, p. 80) pela promoção de uma hermenêutica que constitui o "real" por meio da legitimação de uma vasta pluralidade de vozes (FRASCATI-LOCHHEAD, 1998, p. 161). Afinal, a filosofia hermenêutica moderna nasceu na Europa, não só porque focaliza a atenção sobre o fenômeno da interpretação, mas também porque a base cultural europeia foi a ideia da encarnação de Deus: $O$ cristianismo introduz no mundo o princípio da interioridade, com base no qual a realidade "objetiva" perderá pouco a pouco o seu peso determinante. A frase de Nietzsche "não há fatos, apenas interpretações" e a ontologia hermenêutica de Heidegger não farão mais que levar tal princípio às suas consequências extremas (RORTY \& VATTIMO, 2006, p. 67).

Vattimo associa a kénosis com a dissolução do poder dos fundamentos e a "superação" da metafísica. Essa "superação", contudo, não se configura numa abdicação ou negação da metafísica e sim num reconhecimento e numa rememoração (Andenken) da errância metafísica em direção à sua "distorção". A regenerativa "distorção transformadora da metafísica" (Verwindung) é como uma "convalescença". A Verwindung, através de "cáritas da secularização", representaria a cura de uma doença: a metafísica (VATTIMO, 2002, p. 28). Assim, a convalescença indica uma trilha filosófico-teológica sobre o "religioso" que exclui a pretensão metafísica de aceder a um óntos ón platônico e seu implícito vínculo com uma lógica violenta que silenciaria os que forem considerados "heréticos" sobre a essência divina (VATTIMO, 2004, p. 53).

Vattimo entende que a Verwindung de Heidegger descreve essa "superação", através da secularização. A secularização não rompe com o passado, mas nos "cura" de um objetivismo historiográfico ao recontar caritativamente a história como uma retomada enfraquecida do passado por meio de uma Verwindung (FRASCATI-LOCHHEAD, 1998, p. 81). Essa atitude de retomada caritativa e criativa do passado é um processo emancipatório que ocorre por meio da escuta da tradição, Vattimo chama de pietas - no sentido moderno de "piedade" e "compaixão" - a esse tipo de sentimento de respeito pela tradição, que é transmitida para nós em sua caducidade. Por meio dessa escuta fraca da tradição, a secularização e a pietas promovem uma contínua reinterpretação não- 
proposicional e não-fundamentalista da kénosis divina e de sua mensagem de caridade e solidariedade, que se efetiva numa secularização enfraquecedora e democratizante da "tradição cristã" ou do "cristianismo".

A secularização preconizada por Vattimo participa de uma lógica de distorção e conservação (Verwindung) de duas formas absolutas de compreensão do conceito de "secularização". Sem a "superação" proposta por Vattimo teríamos uma dupla maneira metafísica de se entender a secularização, em que ambas as maneiras trazem a ideia de "fundamento" [GIRARD \& VATTIMO, 2010, p. 151): 1) a "reativa": no sentido tradicionalista da "perda" de Deus como fundamento, pois o modernismo teria rompido com a concepção pré-moderna de Deus; 2) a "triunfalista": no sentido de um "novo" fundacionalismo: as verdades científicas modernas desafiaram epistemologicamente as crenças e os sistemas religiosos, vencendo-as. Uma vitória que se radicalizou em dois movimentos contrários à religião: o cientificismo e o lluminismo (FRASCATlLOCHHEAD, 1998, p. 152). O conflito entre religião e ciência, contudo, não faz sentido hoje em dia. A ideia de "desencantamento" foi radical e paradoxalmente desencantada em seu ideal iluminista e em sua "fé" na história concebida como um progresso linear e irreversivel (FRASCATI-LOCHHEAD, 1998, p. 132); em resumo pode-se dizer que é um mito o ideal de liquidação do mito (VATTIMO, 1998, p. 18).

Não se visa, por conseguinte, com o conceito de secularização, nem o restabelecimento objetivista do passado nem uma pretensão cientificista em se negar o valor do mito. $O$ que se pretende é enfatizar a secularização como uma contínua retomada idiossincrática de mensagens do passado (FRASCATI-LOCHHEAD, 1998, p. 81) - como no aforismo nietzschiano (2000, p. 32) intitulado "Como o mundo verdadeiro acabou virando uma fábula". Uma retomada que se vive numa atitude de piedade dessa transmissão (Überlieferung) fraca da tradição e numa abertura para sempre novas possibilidades (FRASCATI-LOCHHEAD, 1998, p. 56). Sob influência da perspectiva heideggeriana em seu pensamento, Vattimo faz uma conexão entre a pietas e a Verwindung da metafísica. Pietas não significa nem uma presentificação entitativa do tempo e nem uma ideia representativa trazida pela memória como uma faculdade da alma, conforme a tradição escolástica medieval. Assim, pietas é uma rememoração (Andenken) que não se esquece da diferença ontológica apontada por Heidegger. 


\section{3 - A pietas como escuta da tradição quenótica}

Vattimo busca uma paradoxal tentativa de salvar as mensagens valorativas do passado sob a deflacionada forma do diálogo; afinal, todos os sistemas de valores são produções humanas. Para tanto, a pietas configura-se no filtro hermenêutico da tradição ocidental que recusa posições exclusivistas (VATTIMO, 1998, p. 59). Esse filtro, porém, não exclui uma pluralidade de pontos de vista sobre o passado, muito pelo contrário. A pietas é propriamente uma atitude de escuta compassiva das histórias de minorias e de suas culturas que reafirma continuamente a contingência de qualquer interpretação de suas tradições.

Desdobrando a argumentação de nosso autor, vislumbrar essa rememoração como produtora de "realidade" é interpretar o "real" em sua oscilação e temporalidade, seja a exemplo do que se apresenta como monumento ou conforme a precariedade cultural do que se concebe como ornamental. Tanto os ornamentos quanto os monumentos são contaminados pela caducidade de um evento ou realidade. Nesse horizonte historicizante, monumento é algo que se caracteriza por um caráter paradoxal, qual seja: a duração no tempo de algo que faz referência à outra época. Nisto estaria a tautologia da expressão "monumento histórico"; pois, a historicidade de um monumento revela um "mundo" que já passou e que se manifesta à maneira de uma ruína do passado. Nesse sentido, o uso do termo "monumento", na visão de Vattimo, indicaria uma situação ou instituição que se prolonga no tempo não por seu poder e sim pela perda de seu poder político-social. Isso revela como os monumentos trazem, de modo enfraquecido, os vestígios do passado, estimulando novas e contínuas retomadas da história (VATTIMO, 2002, p. 73-84).

A pietas mostra uma eficácia interpretativa do pensiero debole vattimiano para compreender questões referentes ao fenômeno religioso atual. Ilustremos a pujança desse conjunto conceitual por meio de um tema ainda bastante polêmico: o uso de símbolos religiosos em lugares públicos. Analisemos o uso do crucifixo em lugares públicos para exemplificar o que foi dito. Nesta empreitada, procuraremos acompanhar a utilização vattimiana dos termos pietas e Andenken como ferramentas conceituais. Como um produto histórico, social e cultural, a religião deve ser capaz de ouvir os "sinais dos tempos" (VATTIMO, 1998, p. 62). - expressão tirada do Evangelho. Dessa forma, o cristianismo deve repensar a revelação em termos secularizados (VATTIMO, 1999, p. 75). 
O incentivo da laicidade na sociedade pluralista participa da herança cristã, relativizando qualquer "sagrado natural" e suas formas de religião sacrifical [GIRARD \& VATTIMO, 2010, p. 28).

$\mathrm{Na}$ situação atual de laicidade e secularização, os crucifixos servem como monumentos de uma época que se foi: quando a Igreja Católica tinha o status de oficialidade. Portanto, paradoxalmente, caso houvesse uma obsessão pela retirada desses adereços seria dado uma ênfase descabida a adereços culturais que já não funcionam como um símbolo de poder de uma hierarquia eclesiástica. Ao contrário, tais adereços se esvairiam pela redução a elementos culturais que se percebem distraidamente, compondo o conjunto arquitetônico de uma construção antiga. Acompanharíamos aqui a síntese feita por nosso autor entre a expressão benjaminiana de "percepção distraída" (BENJAMIN, 1993) e os conceitos de "ornamentalidade" e "monumentalidade", que são coextensivos entre si (VATTIMO, 2002, p. 82-83).

Bem diferente dessa perspectiva seria o caso de crucifixos em escolas públicas construídas recentemente, num contexto de significativa diversidade cultural religiosa. Num caso assim, a exclusividade de símbolos religiosos de uma única tradição religiosa manteria o privilégio de um grupo em detrimento de outros grupos religiosos, o que seria inconstitucional num Estado laico. $\bigcirc$ Estado laico é neutro em matéria religiosa e não pode fazer da representação simbólica de um grupo religioso um modo de valorizar determinadas instituições religiosas em detrimento de outras. Por isso, o contexto político-cultural em que os símbolos religiosos são usados determinaria a qualidade forte ou fraca - respectivamente, enquanto "símbolos sagrados" e/ ou "adereços culturais" - de sua presença em órgãos públicos de um Estado laico (VATTIMO, 2002, p. 82).

No caso de se considerar a dimensão religiosa tão-só uma esfera cultural dentre outras na sociedade democrática, poderíamos ler essa dimensão na linha da kénosis, isto é, de um enfraquecimento das instituições eclesiásticas em seu poder jurídico-político de definir o que seria ou não o "verdadeiro cristianismo". Neste ponto de vista, ao se defender uma leitura do cristianismo como uma produção histórica e cultural, certas teologias de cunho metafísico dizem que, nesse caso, haveria um esvaziamento e uma redução inadmissíveis da mensagem eterna e verdadeira do divino conforme as conveniências e opiniões socioculturais. Nesta visão, a única forma de a institucionalidade eclesiástica legitimar esse enraizamento cultural seria usando a ideia de "raiz cultural" como 
estratégia retórica de fortalecimento jurídico-político da institucionalidade religiosa que esconderia uma cruzada contra a laicidade e a secularização.

O uso do crucifixo apenas é passível de tolerância pelo Estado Democrático de Direito se ele for considerado como algo culturalmente frágil e difuso, sem relevância político-institucional. Em outras palavras: a presença de crucifixo seria tão-só uma espécie de ornamento cultural que não se refira ao poder da hierarquia eclesiástica ante uma sociedade efetivamente laica, plural e democrática. Por isso, ao se admitir o crucifixo em espaços públicos, há de se assinalar tal objeto em seu caráter ornamental e monumental, assinalando o esvaziamento político da institucionalidade religiosa, culturalizando os símbolos religiosos (GUARINO, 2009, p. 70). Culturalização que indicaria uma religiosidade que salutarmente se esvaiu como um fundo musical, vago e difuso, de uma tradição cultural.

A relação entre laicidade e cristianismo passa pelo princípio enfraquecedor da cáritas, que não se pretende um princípio último e definitivo da realidade (VATTIMO, 1999, p. 64), visto que há apenas "realidades" a serem descobertas no curso dialogante entre múltiplos discursos e interpretações. A construção retórica e metafórica do "real" tem sido reconhecida a partir da "superação" hermenêutica do objetivismo em vista de uma pluralidade de culturas e línguas. Na visão do Livro I da Metafísica de Aristóteles em que o Ser se diz de múltiplas maneiras -, a "pluralidade" é um elemento estrutural do ser, e não um evento-destino (VATTIMO, 2002, p. 23). Há de se reconhecer uma atitude emancipatória na multiplicidade "caótica" de interpretações a respeito da religião, em vista de uma política cultural abrangente e inclusiva (VATTIMO, 1999, p. 29). A cáritas atuante na Epístola aos Hebreus - Deus falou muitas vezes e de várias maneiras aos nossos antepassados por meio dos profetas, mas em nossa época, os últimos dias, ele nos falou por seu Filho (Hb 1:1-2a) - desloca o ser em direção a uma dinâmica histórica de solidariedade e caridade. Por isso, a visão cristã de "pluralidade" esvazia a indiferença metafísica e a objetivação dos outros, servindo como incentivo a atual pluralidade de visões de mundo (GUARINO, 2009, p. 26).

Em resumo, o autor torinense reconhece a fonte cristã da hermenêutica contemporânea, que entende o "mundo" como um grande bazar interpretativo [GUARINO, 2009, p. 104]). Ao "superar" o objetivismo metafísico, a secularização proporcionou uma abertura para inúmeras interpretações e opiniões sobre o "real" sob o 
princípio cristão da cáritas (GIRARD \& VATTIMO, 2010, p. 16). Vattimo sintetiza esse processo pela expressão "cáritas da secularização", ou seja, a secularização trazida pelo princípio da cáritas. Assim sendo, há uma circularidade entre cristianismo, cáritas e secularização. Foi a cáritas que fez a ponte entre a kénosis (o auto esvaziamento de Deus) e a sua efetividade histórica, a secularização. Desde uma enorme gama de abordagens e ressignificações de cada um destes três termos, podemos resumir esse amplo movimento hermenêutico como uma culturalização democrática do cristianismo. Uma forma especial de a religião se vincular à democracia é a sua secularização, transformando a crença numa "(pluri) produção cultural", ao invés de entender a cultura como uma "produção do religioso". Essa culturalização do religioso absorve o efeito da fusão entre "secularização" e "diversidade cultural religiosa" para promover uma sociedade democrática, dissolvendo uma leitura exclusivista e linear da história.

A democracia estimula múltiplos olhares e discursos, abraçando minorias religiosas. A existência de diversas abordagens para a religião é um sinal de democracia e liberdade. Por isso a necessidade de transformar a intolerância metafísica em prol de outra tradição: a da solidariedade e da democracia (CAPUTO \& VATTIMO, 2009, p. 35). Essa solidariedade seria, portanto, a "verdade" do cristianismo kenótico e enfraquecido (CAPUTO \& VATTIMO, 2009, p. 98). Essa "verdade" kenótica implica numa noção evanescente e efêmera da verdade (GUARINO, 2009, p. 17) que visa tão-só elaborar uma interpretação útil à sociedade. Utilidade que se traduz numa maior hospitalidade na vida em comum (VATTIMO, 1999, p. 44). Eis a "universalidade" trazida pelo cristianismo fraco, que não é a universalidade do colonialismo, mas a da hospitalidade e o entendimento mútuo pelo estímulo à multiplicação de vozes, sem que cada uma delas perca a singularidade de seus respectivos sotaques (VATTIMO, 2002, p. 101).

\section{Considerações finais:}

Há de se conceber uma reinvenção do religioso e essa reinvenção passa por uma nova abordagem do fenômeno religioso. O rebaixamento de Deus ao nível do humano se coaduna com a dissolução da metafísica e a "superação" da ontoteologia, favorecendo o "retorno" do cristianismo (RORTY \& VATTIMO, 2006, p. 104). Num reconhecimento valorativo da continuidade histórica entre o ato da encarnação e a secularização, Vattimo 
entrelaça a doutrina da encarnação com a cáritas, fazendo desta o critério de dissolução de todo pensamento fundante sobre o ser e de valorização de uma crescente pluralidade democrática.

Essa linha de raciocínio acompanha a de outros autores (GEERING, 2002, p. 9697) na aceitação da hipótese weberiana (2004) de que o mundo moderno, democrático e secularizado tem sido parcialmente moldado pelo cristianismo de viés protestante. Vattimo se baseia na conexão entre protestantismo e secularização para formular uma defesa paradoxal de que a secularização caracterizaria a história da salvação inaugurada pela kénosis (VATTIMO, 2004, p. 63). A kénosis estaria na base, por exemplo, do movimento de enfraquecimento da Cristandade pela Reforma Protestante graças à ação secularizante, minando a retórica de unicidade sócio-político da Cristandade.

Tal enfraquecimento fragmentou o cristianismo em inúmeras interpretações de sua tradição, que, por sua vez, diluiu-se numa emancipatória abertura a outros horizontes culturais e religiosos. Eis o paradoxo dessa religião, que promove o ideal de igualdade e fraternidade - de que não há judeu nem grego $[\mathrm{Gl} 3,27]$ e de que o amor é a única lei [cf. Cl 3, 14; Rm 13, 10] - para a emergência da pluralização democrática das diferenças até se enfraquecer pelo reconhecimento da legitimidade de outras tradições religiosas. Nesta circularidade, a Cristandade - que Kingsley chamou de "cristianismo muscular" (TAYLOR, 2007, p. 396) - reduz-se à sua ética caritativa, quando então se transfigura numa espécie de "fundo musical" da vida democrática. Neste sentido, Rorty - amigo de Vattimo e que se tornou um importante interlocutor (VATTIMO, 2009, p. 98) - cita Nietzsche para concordar com ele de que a democracia seria o cristianismo tornado natural [RORTY \& VATTIMO, 2005, p. 99).

Alguns autores (ABEYSEKARA, 2008, p. 9), porém, discordam dessa "lógica de herança" no pensamento de Vattimo, ou seja, a defesa de que um cristianismo fraco e secular teria superado o modelo da Cristandade, cujo suporte teórico era de cunho metafísico. De qualquer modo, apesar de Charles Taylor não perceber a história do Ocidente como um "progresso inevitável e uniforme de secularização" (WRATHALL, 2003, p. 4), este filósofo concorda que a secularização trouxe uma fratura progressiva no entendimento unificado do Ser transcendente. Assim, a oposição entre o "mundo secular" e "religioso" sinalizaria a marginalização do patrimônio religioso do Ocidente e de seus símbolos cristãos ante a nova atmosfera cultural trazida pelo capitalismo (TAYLOR, 2008, 
p. 189). Poderíamos inferir com Vattimo, no entanto, que a atual fragmentação cultural que vivemos é, ao mesmo tempo, consequência do "cristianismo" e independente dele.

A secularização enfraquece e supera a metafísica por pluralizar as opiniões, o que relativiza qualquer exclusivismo religioso ou raízes culturais (VATTIMO, 2002, p. 95). Proclamar que o cristianismo está na base cultural do Ocidente não significa um exclusivismo dessa religião. Exclusivismo cultural que justifique certa unilinearidade histórica em contraposição a outras culturas e religiões [GIRARD \& VATTIMO, 2010, p. 41). Muito pelo contrário. A kénosis secularizou o Ocidente e contribuiu para um clima de tolerância. Tolerância que se iniciou pela tolerância religiosa para se estender a um incremento da democracia e da diversidade cultural na condição atual da modernidade tardia. A secularização democrática partiu de um tipo enfraquecido de cristianismo, oposto à Cristandade e à sua metafísica da cultura. Logo, o pluralismo e a secularização seriam frutos das múltiplas "raízes cristãs" no Ocidente que enfraqueceram o modelo metafísico e ahistórico de fundamentação cultural e religiosa. Daí se encontra o valor de um discurso pós-metafísico acerca do religioso. Discurso que torna a hermenêutica vattimiana uma extensão cultural e democrática de um cristianismo monumentalizado e fragilizado pela secularização trazida pela kénosis, cristianismo que, ao mesmo tempo, promove e vive em paz com a pluralidade de culturas e religiões.

\section{Referências Bibliográficas:}

ABEYSEKARA, Ananda. The Politics of Post secular Religion: Mourning Secular. Futures. Columbia University Press: New York, 2008.

BENJAMIN, Walter. A obra de arte na época de suas técnicas de reprodução. In: BENJAMIN, Walter; HORKHEIMER, Max; ADORNO, Theodor W.; HABERMAS, Jürgen. Textos escolhidos. São Paulo: Abril Cultural, 1993.

CAPUTO, John. \& VATTIMO, Gianni. After the Death of God. New York: Columbia University Press, 2009.

DERRIDA, Jacques. \& VATTIMO, Gianni. A Religião. O Seminário de Capri. São Paulo, Estação Liberdade, 2000, 232 p. 
FRASCATI-LOCHHEAD, Marta. Kenosis and Feminist Theology: The Challenge of Gianni Vattimo. Albany: State University of New York Press, 1998.

GEERING, Lloyd. Christianity without God. Santa Rosa: Polebridge Press, 2002.

GIRARD, René. A Violência e o Sagrado. São Paulo: Edunesp, 1991.

\& VATTIMO, Gianni. Christianity, Truth, and Weakening Faith: A Dialogue.

New York: Columbia University Press, 2010.

GUARINO, Thomas. G. Vattimo and Theology. London: T \& T Clark, 2009.

NIETZSCHE, Friedrich. A Gaia Ciência. São Paulo: Hemus, 1981.

. Crepúsculo dos Ídolos. Rio de Janeiro: Relume Dumará, 2000.

RICOEUR, Paul. Leituras 3 - As Fronteiras da Filosofia. São Paulo: Loyola, 1996.

RORTY, Richard \& VATTIMO, Gianni. O Futuro da Religião - solidariedade, caridade e ironia. Rio de Janeiro: Relume Dumará, 2006.

TAYLOR, Charles. A Secular Age. Cambridge: Harvard University Press, 2007. . Religion: Beyond a Concept. New York: Fordham University Press, 2008.

VATTIMO, Gianni. Acreditar em Acreditar. Lisboa: Relógio D’Água, 1988.

A sociedade transparente. Relógio D’Água: Lisboa, 1992.

Depois da Cristandade. Rio de Janeiro/São Paulo: Record, 2004.

. O fim da modernidade. São Paulo: Martins Fontes, São Paulo, 2002.

. Para Além da Interpretação - O significado da hermenêutica para a filosofia. Rio de Janeiro: Tempo Brasileiro, 1999.

WEBER, Max. A ética protestante e o "espírito" do capitalismo. São Paulo: Companhia das Letras, 2004.

WRATHALL, Mark A. (ed.). Religion after Metaphysics. Cambridge: Cambridge University Press, 2003. 